\title{
Diversity analysis of some selected rice genotypes through SSR- based molecular markers
}

\author{
M. H. Shahriar ${ }^{1}$, A. H. K. Robin ${ }^{1 *}$, S. N. Begum ${ }^{2}$ and A. Hoque ${ }^{1}$ \\ ${ }^{1}$ Department of Genetics and Plant Breeding, Bangladesh Agricultural University, Mymensingh- 2202 and ${ }^{2}$ Plant \\ Breeding Division, Bangladesh Institute of Nuclear Agriculture, Mymensingh-2202, Bangladesh \\ *E-mail: gpb21bau@gmail.com
}

\begin{abstract}
An experiment was carried out to assess the genetic diversity of advanced rice (Oryza sativa L.) breeding lines using three SSR markers viz., RM147, RM167 and RM215. Thirty T- aman advanced breeding lines at $F_{9}$ generation along with 4 check varieties were assessed. All three primers showed polymorphism. A total of 29 alleles were detected among the rice genotypes with an average of 9.67 alleles per locus. Polymorphism information content (PIC) ranged from 0.47 to 0.88 with an average of 0.71 . A dendrogram was constructed based on total microsatellite polymorphism and 34 genotypes were grouped into four major clusters at 0.36 similarity co-efficient differentiating the early maturing genotypes from the late maturing types. The information about the genetic diversity might be utilized in future breeding programs for developing rice varieties with much shorter growth duration. The results also suggested that microsatellite markers which are linked to genes or QTLs responsible for growth duration properties are suitable tools for marker assisted selection (MAS) to select the rice genotypes of shorter growth duration.
\end{abstract}

Keywords: Rice, SSR marker, Polymorphism, Genetic diversity, Advanced breeding lines

\section{Introduction}

Bangladesh is a predominantly rice-based agricultural country. Rice being the most dominant food crop of Bangladesh accounted for 75 percent of agricultural land use and 28 percent of GDP (Anonymous, 1998). Rice-based agriculture currently occupies about $90 \%$ space in a cropping pattern nearly in all rice growing regions. In fact, rice-rice-rice crop rotation has forcibly occupied cropping fields to feed hungry teeming millions of Bangladesh. To increase crop diversity and to bring change in rice based cropping patterns, especially designed breeding schemes are often needed. These include developing of short duration, salt-tolerance, drought tolerance, disease resistance, and high protein or mineral content rice varieties.

Molecular markers are the powerful tools to detect genetic variation and genetic relationship within and among species. DNA markers are unmasking new genes for the improvement of crop varieties (Causse et al., 1994). Generally, microsatellite loci are known as simple sequence repeats (SSRs) and these are the most popularly employed molecular markers (Litt and Lutty, 1989). They are basically PCR dependent markers which are efficient, convenient, cost effective as well as abundant, co-dominant, highly reproducible. SSRs can effective even in trace amount and also can interspersed throughout the genome (Panaud et al., 1996, Temnykh et al., 2000). In organisms, specific characters are represented by specific sequences and those sequences are easily identified by SSRs (Levinson and Gutman, 1987). Charismatic polymorphism and its degree of presence are also detected by SSRs markers (Ni et al., 2002). That's the reason, why microsatellite markers have been widely applied in rice genome studies as well as allelic diversity analysis (McCouch et al., 1997).

Keeping this point in view, the present investigation was undertaken to assess the genetic diversity of 30 advanced rice lines along with the check varieties to screen out the short duration lines and to select diversified parents for having desirable genotypes in segregating generations in future.

\section{Materials and Methods}

The experiment was carried out at the Biotechnology Laboratory of Bangladesh Institute of Nuclear Agriculture (BINA) during the period of March- May 2014. 


\section{Plant materials}

Seeds of 30 advanced breeding lines of $\mathrm{T}$. aman rice along with 4 check varieties were collected from the Department of Genetics and Plant Breeding, Bangladesh Agricultural University, Mymensingh (Table 1). Seeds were germinated in a controlled room by incubating those at $30^{\circ} \mathrm{C}$ in petridishes.

Table 1. A list of the genotypes used in the experiment

\begin{tabular}{|c|c|c|}
\hline SL. & Germplasms & Sources \\
\hline R1- R30 & GPB accession, BAU & GPB, BAU \\
\hline R31 & BINA dhan 7 & BINA, Mymensingh \\
\hline R32 & BRRI dhan 39 & BRRI, Gazipur \\
\hline R33 & BRRI dhan 49 & BRRI, Gazipur \\
\hline R34 & BRRI dhan 57 & BRRI, Gazipur \\
\hline
\end{tabular}

Note: GPB $=$ Department of Genetics and Plant Breeding, BAU= Bangladesh Agricultural University, BRRI= Bangladesh Rice Research Institute, BINA= Bangladesh Institute of Nuclear Agriculture

\section{Collection of leaf samples}

Young, vigorously growing fresh leaf samples were collected from 25 days old seedling of each of the thirty four genotypes which were used as the source of genomic DNA. Initially healthy portion of the youngest leaves of the seedlings were cut apart with a pair of sterilized scissors and washed in distilled water and ethanol and dried on a fresh tissue paper to remove spore of microorganisms and any other source of foreign DNA. Collected leaf samples were then put into polythene bags and kept on ice in an ice box. Tag was maintained for each sample. After that, the polythene bags were wrapped by aluminium foil and stored at $-80^{\circ} \mathrm{C}$ freezer.

\section{Genomic DNA isolation}

DNA was extracted from the leaves of each genotype using the Cetyl Trimethyl Ammonium Bromide (CTAB) mini-prep method (Stewart and Via, 1993).

\section{SSR Protocol}

PCR amplification of SSR markers was undertaken using three primer pairs enlisted in Table 2. Each of PCR reaction tube contained $3.4 \mu \mathrm{L} \mathrm{ddH}_{2} \mathrm{O}, 3 \mu \mathrm{L}$ template DNA, $0.2 \mu \mathrm{L}$ dNTPs, $1.2 \mu \mathrm{L} \mathrm{MgCl}, 0.2 \mu \mathrm{L}$ Taq polymerase, and $0.5 \mu \mathrm{L}$ each of forward and reverse primers. Amplification was executed using the following conditions: preheated at $94^{\circ} \mathrm{C}$ for 3 minutes, 40 cycles of 1 minute denaturation at $94^{\circ} \mathrm{C}, 1$ minute annealing at $55^{\circ} \mathrm{C}, 2$ minutes elongation at $72^{\circ} \mathrm{C}$ and a final extension at $72^{\circ} \mathrm{C}$ for 7 minutes. The SSR amplification products were separated through a vertical polyacrylamide gel electrophoresis unit. DNA fragments were expressed using ethidium bromide staining procedure. The gels were stained for 20 minutes. After that gels were documented using gel documentation unit (UV-trans-illuminator).

Table 2. Polymorphic SSR primers used in the present study for diversity analysis

\begin{tabular}{|c|c|c|c|c|}
\hline Locus & Forward Primer & Reverse Primer & AT $\left({ }^{\circ} \mathrm{C}\right)$ & PS (bp) \\
\hline RM147 & TACGGCTTCGGCGGCTGATTCC & CССССGAАTCCСАTCGAAACCC & 55 & 97 \\
\hline RM167 & GATCCAGCGTGAGGAACACGT & AGTCCGACCACAAGGTGCGTTGTC & $55-60$ & 128 \\
\hline RM215 & CAAAATGGAGCAGCAAGAGC & TGAGCACCTCCTTCTCTGTAG & 55 & 148 \\
\hline
\end{tabular}

Note: AT= Annealing temperature, PS= Product size, position and number of repeats as previously published (http://www.gramene.org) 


\section{SSR data analysis}

The size of most intensely amplified fragments was determined by comparing the migration distance of amplified fragments relative to the molecular weight of known size markers and 25 base pairs (bp) DNA ladder using AlfaView software. The number of alleles per locus, major allele frequency, gene diversity, PIC, Nei's genetic identity and genetic distance values were calculated using PowerMarker version 3.25. MEGA5.22 software was used to construct a UPGMA (Unweighted Pair Group Method with Arithmetic Averages) dendrogram showing the distance-based inter-relationship among the genotypes.

\section{Results and Discussion}

In this experiment, all of three SSR motifs were polymorphic and produced varying number of alleles with different size ranges (Fig. 1). A total of 29 alleles were identified at the loci of 3 primers across 34 rice genotypes (Table 3). The number of alleles per locus ranged from 7 to 13 per locus. The locus RM147 had the highest number of alleles (13) and RM167 contained the lowest number of alleles (7). The average value of alleles is 9.67 per locus. The overall size of amplified products ranged from $76 \mathrm{bp}$ in locus RM147 to 152 bp in locus RM215. On an average, 38\% of the 34 rice genotypes shared a common major allele ranging from 17\% (RM167) to 70\% (RM147) common allele at each locus. A moderate level of diversity was obtained which ranged from 0.48 to 0.89 with an average of 0.73 among those 3 loci.
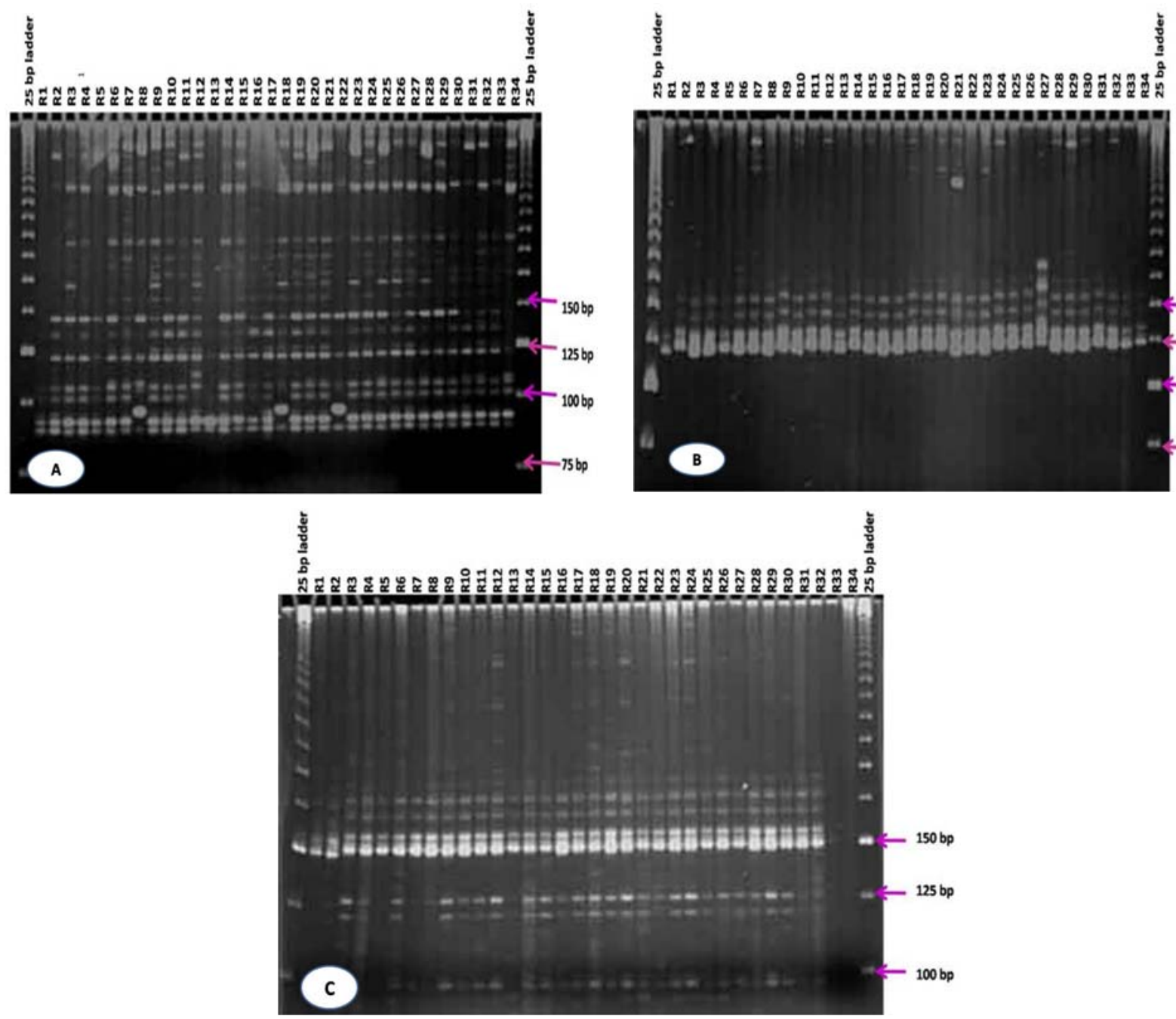

Fig. 1. SSR profile of 34 rice genotypes using primers RM147 (A), RM167 (B) and RM215 (C) respectively 
Polymorphism information content (PIC) value is a reflection of allele diversity and frequency among the varieties. PIC value of each marker can be evaluated on the basis of its alleles. PIC varied significantly for all the studied SSR loci. In the present study, the level of polymorphism among the 34 genotypes was evaluated by calculating PIC values for each of the 3 SSR loci. The PIC values ranged from 0.47 (RM147) to 0.88 (RM167) with an average of 0.71 per locus (Table 3). These results revealed that markers RM167 would be the best in screening 30 rice genotypes followed by RM215 and RM147.

Table 3. Details of SSR markers showed polymorphism, indicating their location on rice chromosomes, number of alleles detected, allele size range, diversity and polymorphism information content (PIC)

\begin{tabular}{|c|c|c|c|c|c|c|}
\hline Marker & Chromosome & No. of allele & Frequency & Size range (bp) & Gene diversity & PIC \\
\hline RM147 & 10 & 7.00 & 0.70 & $85-92$ & 0.48 & 0.47 \\
\hline RM167 & 11 & 13.00 & 0.17 & $120-135$ & 0.89 & 0.88 \\
\hline RM215 & 9 & 9.00 & 0.26 & $140-148$ & 0.81 & 0.79 \\
\hline Mean & \multicolumn{7}{|l|}{0.38} & & 0.73 & 0.71 \\
\hline
\end{tabular}

Note: $\mathrm{PIC}=$ Polymorphism Information Content

Genetic similarities were calculated from the data of Nei's coefficient. The similarity matrix was used to determine the level of relatedness among the studied genotypes. Pair-wise estimates of similarity ranged from 0.00 to 1.00 and the average similarity among all 34 cultivars was 0.36 .

UPGMA method was used for cluster analysis to differentiate the studied genotypes into groups based on similarity co-efficient. Four clusters were made at genetic similarity level of $0.3-0.4$ (Fig. 2). Cluster I, II, III and IV contained 8, 22, 2 and 2 genotypes respectively. The days to maturity of the genotypes of cluster I ranged from 112 to 119 days indicating all genotypes in this group were of comparatively shorter growth duration than the genotypes of other clusters (Fig. 2). This cluster includes the genotype R7 which required only 112.7 days for maturity (Shahriar et al., 2014). Cluster II comprised of 21 advanced breeding lines and one check variety (BINA dhan 7). It is a cluster of mixture of short, intermediate and long duration genotypes with good yielding capability. A check variety (BRRI dhan 39) and a single advanced breeding line (R29) are included in cluster III. R29 had the highest filled grain capability. Cluster IV comprised of 2 check varieties viz., BRRI dhan 49 and BRRI dhan 57.

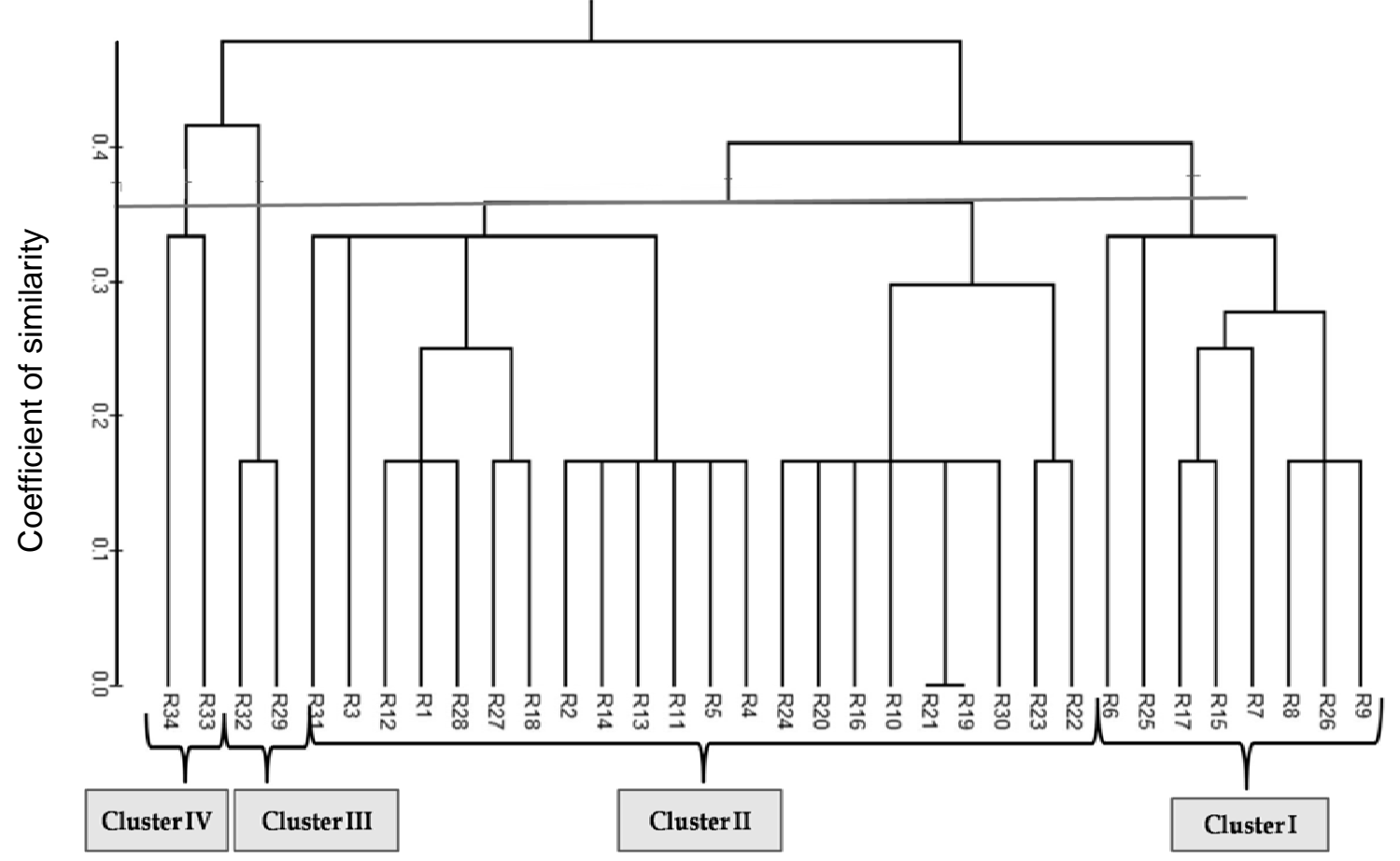

Fig. 2. UPGMA cluster dendrogram showing the genetic relationship among 34 rice genotypes 


\section{Conclusion}

An SSR based screening to 34 rice genotypes using 3 markers selected a total of 29 alleles with an average of 9.67 alleles per locus. The highest PIC value was recorded for primer RM167 and that was the lowest for the primer RM147. Thirty four genotypes were grouped into 4 clusters where the genotypes of cluster 1 (8 genotypes including the earliest maturing genotype R7) were of shorter growth duration. SSR markers used in this study were convenient, neutral \& co-dominant in nature.

\section{Acknowledgements}

The authors gratefully acknowledge the comments and suggestions of Professor Dr. Md. Wazuddin, Professor Dr. Ujjal Kumar Nath and Dr. Mirza Mofazzol Islam during the study period.

\section{References}

Anonymous, 1998. "Bangladesh: A Country Study: Rice". Library of Congress, Washington D.C.

Causse, M.A., Fulton, T.M., Cho, Y.G., Ahn, S.N. and Chunwongse, J. 1994. Saturated molecular map of the rice genome based on an interspecific backcross population. Genetics, 138: 1251-1274.

Levinson, G. and Gutman, G.A. 1987. Slipped-strand mis-pairing: a major mechanism of DNA sequence evolution. Molecular Biology and Evolution, 4: 203-221.

Litt, M. and Luty, J.A. 1989. A hyper variable microsatellite revealed by in vitro amplification of a dinucleotide repeat within the cardiac muscle acting gene. American Journal of Human Genetics, 44: 397-401.

McCouch, S.R., Chen, X., Panaud, O., Temnykh, S., Xu, Y., Cho, Y.G., Huang, N., Ishii, T. and Blair, M. 1997. Microsatellite marker development, mapping and applications in rice genetics and breeding. Plant Molecular Biology, 35: 89-99.

Ni, J., Colowitand, P.M. and Mackill, D.J. 2002. Evaluation of genetic diversity in rice subspecies using microsatellite markers. Crop Science, 42: 601-607.

Panaud, O., Chenayd, X. and McCouch, S.R. 1996. Development of microsatellite markers and characterization of simple sequence length polymorphism (SSLP) in rice (Oryza sativa L.). Molecular and General Genetics, 252: 597-607.

Shahriar, M., Robin, A. and Hoque, A. 2014. Diversity assessment of yield, yield contributing traits, and earliness of advanced Taman rice (Oryza sativa L.) lines. Journal of Bioscience and Agriculture Research, 01(02): 101-111.

Stewart, Jr, C. N. and Via, L.E. 1993. A rapid CTAB DNA isolation technique useful for RAPD fingerprinting and other PCR applications. Biotechniques, 14(5): 748-750.

Temnykh S., Park W.D., Ayers N., Cartinhour S., Hauck N., Lipovich L., Cho Y.G., Ishii T. and McCouch, S.R. 2000: Mapping and genome organization of microsatellite sequence in rice (Oryza sativa L.). Theoretical and Applied Genetics, 100: 697-712. 